when the train was close to the seismograph, and continued visible until the train had passed off the bridge at the other end.

\section{DOES PRECIPITATION INFLUENCE THE MOVEMENT OF CYCLONES?}

IN Prof. Elias Loomis's first " Contribution to Meteorology," in the American Journal of Arts and Science, he examined the distribution of rain around 152 storms (cyclones) in the United States, in order to determine whether there exists any relation between the velocity of a storm's progress and the extent of the accompanying rain area. He found that "the average extent of the rain area on the east side of the storm's centre is 500 miles; and when the rain area extends more than 500 miles, the storm advances with a velocity greater than the mean; but when the extent of the rain area is less than 500 miles, the storm advances with a velocity less than the mean." In his twelfth "Contribution" he examined 39 storms which moved with exceptional velocity (I000 miles or more per day) and found that " the rain area generally extended a great distance in advance of the storm centre, the average distance being 667 miles." Finally, Loomis examined 29 cases of those abnormal cyclones in the United States which moved toward the west. He says: - "In nearly every case we find a fall of rain or snow in the region toward which the low centre advanced, and in most of the cases the rainfall was unusually great.

It may be inferred from these comparisons that the fall of rain or snow is one of the most important causes which determine the abnormal movements of areas of low pressure" (ninth memoir, p. 44). Ley and Abercromby state that in Great Britain the relation of the weather to the cyclone centre is the same whatever the path of the cyclone; thus when storms advance toward the west the greatest cloud development and rainfall is to the west of the cyclone centre. In the Proceedings of the Royal Meteorological Society, vol. xliii., Abercromby gives a table showing the relation between the intensity of "trough phenomena" and the velocity of cyclones. This table indicates very clearly that the greater the velocity of the cyclone the more marked the "trough phenomena." Hence, according to Abercromby's definition of "trough phenomena " the heaviest rain and cloud areas are massed toward the front of rapidly advancing cyclones, while immediately after the passage of the line of minimum pressure the sky begins to show signs of clearing. This is especially well marked in cyclones passing off the northeast coast of the United States. When the cyclones are moving with unusual rapidity, not only all the rain, but almost all of the cloud area is confined to the front half of the cyclone.

Loomis suggested that the excess of rain in front of rapidly advancing cyclones was one of the causes of the rapid advance; but when investigating heavy rainfalls in the United States he concludes that "the forces which impart that movement to the air which is requisite to an abundant precipitation of vapour, instead of deriving increased strength from the great volume of rain, rapidly expend themselves and become exhausted;" and after examining certain cyclones which were accompanied by no rain he adds: "So that it seens safe to conclude that rainfall is not essential to the formation of areas of low barometer, and is not the principal cause of their formation or of their progressive movement." Hann arrives at similar conclusions from investigations in Europe. After investigating an especially heavy rainfall which occurred in Austria and vicinity in August 1880 , he concludes thus:- "The appearance of a barometric minimum in Hungary occasioned abnormal and extended precipitation on the west and north-west side of this barometric cepression. The reaction of this precipitation on the position of the centre of the depression is scarcely perceptible.... We find, therefore, through the investigation of the relative lowest barometer reading in its behaviour to rainfall, that our former conclusions are confirmed" (lxxxii. Bunde d. Wiss. ii. Ab., November 1880). This investigation does not necessarily prove that precipitation does not appreciably influence the movements of cyclones in general, but at least suggests that in the first cases mentioned above the unequal distribution of rain around rapidly moving cyclones was not the cause, but the result of the cyclone's advance. In cyclones which move very slowly, as do tropical cyclones, the air ascends almost uniformly around the centre; but when cyclones have a more rapid progressive motion, the air in the rear, which has not only to enter, but to follow the cyclone, is more retarded by friction than the air in front, and hence does not enter the cyclone so freely, so that the formation of cloud and rain in the rear is retarded; while, on the other hand, a larger volume of new air enters the progressing cyclone in front, and increases the amount of precipitation. Thus, between February I 2 and 14 , a cyclone passed across the American continent with the exceptionally high velocity of 58 miles per hour. During its passage the highest wind velocity reported on any of the United States Signal Service morning weather maps was 40 miles per hour, occurring immediately in the rear of the cyclone at Father Point, Can., on the morning of the I4th. At none of the other I 30 stations did the maps show a wind velocity exceeding so miles per hour during the passage of the cyclone. This is an example of many similar cases which show that in rapidly moving cyclones the air in the rear near the earth's surface does not move as rapidly as the cyclone itself. Hence, it seems evident that the air near the surface immediately in the rear of these cyclones is not air which has followed the cyclone near the surface, but air which has descended from above. Espy showed many years ago that, on account of mechanical heating by compression, no descending air can be accompanied by precipitation; and an explanation is thus afforded why there is none, or but little cloud and precipitation in the rear of rapidly moving cyclones. On the other hand, in order that a cyclone may advance rapidly, there must be a rapid decrease in pressure, and consequently a rapid removal of the air, in front of the advancing depression. Since, according to the normal circulation of a cyclone, there is an inward movement near the earth's surface and an upward and outward movement near the top, this upward and outward movement is necessarily increased in unusually rapid-moving cyclones, and hence also the cloudiness and precipitation are increased.

Hourly observations of cloud movements made during the day hours for nearly two years at Blue Hill Observatory indicate that the velocity of storm movement, and especially the variability of the weather, are intimately connected with the velocity of movement of the general atmosphere.

The writer is hence led to believe that the main cause of rapid cyclone progression is an unusually rapid drifting of the atmosphere over large regions; and the unequal distribution of rain around the cyclone is due to the rapid progress of the cyclone.

Blue Hill Observatory, Boston, June I 8.

\section{H. Helm Clayton.}

\section{NOTES}

Mr. JOHN WhiteHEAD returned to Labuan in safety from his second expedition to Kina Balu, and is daily expected in England. $\mathrm{He}$ ascended the mountain to its summit, and attained to an altitude of 13,500 feet. His collection will contain many novelties, the small portion sent by him in advance to Mr. Bowdler Sharpe exhibiting many curious features. The new species will be clescribed by Mr. Sharpe in the forthcoming 